\title{
HUBUNGAN KARAKTERISTIK BIDAN DENGAN PRAKTIK KEBIDANAN KOMPLEMENTER DI PRAKTEK MANDIRI BIDAN
}

\author{
Ranny Septiani* $\diamond$, Gangsar Indah Lestari* \\ *Jurusan Kebidanan Poltekkes Kemenkes Tanjungkarang \\ $\diamond$ Corresponding Outhor: koeny.rani@gmail.com
}

\begin{abstract}
Penggunaan terapi komplementer merupakan terapi alternatif yang menjadi banyak perhatian banyak negara. Terapi komplementer juga merupakan pendukung pengobatan konvensional atau pengobatan pilihan lain di luar pengobatan medis yang konvensional. Hampir di seluruh dunia, bidan menggunakan terapi komplementer dalam profesi mereka lebih dari praktisi medis lainnya. Sebuah tinjauan pustaka memperkirakan 60 - 100\% bidan telah menggunakan satu atau lebih terapi komplemeter Penelitian ini merupakan penelitian kuantitatif. Populasi dan sampel penelitian adalah semua bidan praktek mandiri di Kota Metro yang berjumlah 52 orang, Pengumpulan data dilakukan dalam satu waktu dengan menggunakan instrumen kuesioner. Data dianalisis dengan analisis univariat dan bivariat. Hasil penelitian ini, 67,3\% bidan telah melakukan praktik kebidanan komplementer, hanya variabel pendidikan yang tidak mempunyai hubungan bermakna terhadap praktik kebidanan komplementer. Saran untuk bidan agar melakukan peningkatan pengetahuan secara formal maupun informal tentang terapi-terapi non konvensional/komplementer sehingga dapat memberikan pelayanan praktik kebidanan komplementer dalam memberikan pelayanan kebidanan.
\end{abstract}

Kata Kunci: Kebidanan,Komplementer

\section{LATAR BELAKANG}

Penggunaan terapi komplementer merupakan terapi alternatif yang menjadi banyak perhatian banyak negara. Saat ini terapi komplementer menjadi bagian penting dalam pelayanan kesehatan di berbagai negara seperti Amerika Serikat dan negara lainnya. Berdasarkan data World Health Organization (WHO) sebanyak $80 \%$ praktisi kesehatan di negara berkembang lebih memilih pengobatan alternatif dibanding pengobatan kimia (WHO, 2012). Terapi Komplementer saat ini dianggap sebagai terapi dengan pendekatan karena menyembuhkan pasien dengan memandang dari berbagai sudut dan beraneka aspek kehidupan. Terapi komplementer juga merupakan cara penanggulangan penyakit yang dilakukan sebagai pendukung pengobatan konvensional atau pengobatan pilihan lain di luar pengobatan medis yang konvensional. Di Amerika Serikat sekitar 627 juta orang merupakan pengguna terapi alternatif dan 386 juta orang merupakan pengunjung praktik konvensional (WHO, 2011). WHO merekomendasikan pengobatan tradisional yang merupakan bagian dari teknik komplementer dalam pemeliharaan kesehatan masyarakat, pencegahan dan pengobatan penyakit terutama untuk penyakit kronis, penyakit degenerative dan kanker. WHO juga mendukung upaya peningkatan keamanan dan khasiat dari obat-obatan tradicional (WHO, 2012).

Di Indonesia sendiri metode-metode pengobatan komplementer telah dikenal lama. Berdasarkan data hasil SUSENAS (Survei Sosial Ekonomi Nasional) tahun 2001, presentase penduduk Indonesia yang menggunakan obat tradisional dalam pengobatan sendiri selama kurun waktu empat tahun (1998-2001) cendrung meningkat dari angka $15,6 \%$ menjadi $30,2 \%$ dan terus meningkat dari tahun ke tahun hingga tahun 2006 menjadi 38,30\% (Supardi et al., 2010).

Banyak alasan klien menggunakan terapi komplementer salah satunya adalah filosofi holistik pada terapi komplementer yaitu adanya harmoni dalam diri dan promosi kesehatan dalam terapi komplementer selain itu alasan lain yang mendasari klien meminta pengobatan dengan terapi komplementer adalah klien ingin terlibat dalam pengambilan keputusan dalam 
pengobatannya. Tidak sedikit klien bertanya tentang terapi komplementer kepada tenaga kesehatan. Hal ini dapat menjadi peluang bagi tenaga kesehatan untuk dapat memberikan terapi komplementer dalam pelayanannya (WHO, 2011).

Bidan merupakan profesi kesehatan yang merupakan ujung tombak pelayanan kesehatan di masyarakat dengan fokus utama kesehatan ibu dan anak. Kesehatan ibu dan anak yang optimal merupakan tujuan akhir dari pelayanan yang diberikan bidan. Di masa kini pelayanan yang diharapkan masyarakat tidak hanya untuk menyembuhkan namun tingkat tertinggi harapan klien adalah kenyamanan yang didapat sehingga efek samping atas pengobatan tidak dirasakan bahkan menjadi tindakan pencegahan kesakitan yang akan diderita. Pelayanan kebidanan diberikan sepanjang siklus kehidupan seorang wanita yang membutuhkan asuhan baik bertujuan promotif, preventif, kuratif hingga rehabilitatif. Hal tersebut dibuktikan Penggunaan Complementer Alternative Medicine (CAM) lebih umum dilakukan oleh wanita sekitar 48,9\% dibandingkan dengan pria sebesar $37,8 \%{ }^{5}$ Hal ini menunjukkan bahwa penggunaan terapi komplementer pada perempuan sebagai indikator penggunaan terapi komplementer di masa yang akan datang.

Hampir di seluruh dunia, bidan menggunakan terapi komplementer dalam profesi mereka lebih dari praktisi medis lainnya. Sebuah tinjauan pustaka memperkirakan $60-100 \%$ bidan telah menggunakan satu atau lebih terapi komplemeter (Hall HG. at.al. 2012) Indikasi umum penggunaan terapi komplementer oleh bidan termasuk induksi persalinan dan augmentasi, mengatasi mual dan muntah, relaksasi, mengatasi nyeri punggung, anemia, mal-presentasi, ketidaknyamanan perineum, depresi postnatal dan masalah laktasi. ${ }^{6}$ Berbagai jenis terapi yang populer direkomendasikan bidan adalah terapi pijat, obat herbal, tehnik relaksasi, suplemen nutrisi, aromaterapi,homeopati dan akupunktur (Eisenberg, D. M.,et.al., 1998). Praktik kebidanan komplementer banyak disetujui untuk dilaksanakan dalam penelitan di New Zeland dan Kanada 71,5\% dari responden menyatakan bahwa CAM merupakan bagian penting dari praktik kebidanan dan mendapat $81,4 \%$ dukungan bidan bahwa CAM dilakukan untuk menghindari intevensi medis (Wootton, J. C., \& Sparber, A., 2001) Dalam mewujudkan tujuan dari pelayanan kebidanan, bidan didukung dengan pengetahuan dan sikap yang baik dan benar serta terampil dalam memberikan pelayanan kebidanan komplementer.

Banyak faktor dari bidan yang dapat mempengaruhi pelaksanaan pelayanan kebidanan komplementer antara lain : usia, masa kerja, latar belakang pendidikan serta pelatihan komplementer kebidanan yang pernah didapatkan serta sumber informasi yang didapat tentang praktik kebidanan komplementer.

\section{METODE}

Rancangan penelitian ini adalah studi anaitik korelasi dengan cross-sectional. Yaitu jenis penelitian yang menekankan pada waktu pengukuran atau observasi data dalam satu kali pada waktu yang dilakukan pada variabel dependen dan variabel independen. Dan penelitian ini menggunakan pendekatan untuk melihat hubungan antara variabel satu dengan variabel lainnya.

Populasi sekaligus sampel dalam penelitian ini adalah seluruh bidan di Praktek Mandiri Bidan di Kota Metro yang diteliti. Pengumpulan data dalam penelitian ini menggunakan data primer yang didapat langsung dari responden dengan menggunakan kuesioner berupa pertanyaan tertutup sebagai alat pengumpul data. Pengolahan data menggunakan beberapa tahapan dimulai dengan editing data, pengkodean, pemberian nilai, memproses data, serta pembersihan data jika terdapat kesalahan-kesalahan atau ketidaklengkapan kode untuk kemudian dilakukan perbaikan atau koreksi data. Analisa data pada penelitian ini menggunakan analisis data univariat berupa distribusi frekuensi dan presentase dari varibael-variabel penelitian 
dan analisis bivariat menggunakan chi square $\left(X^{2}\right)$ dengan nilai kemaknaan $\rho<0,05$.

\section{HASIL}

\section{Analisis Univariat}

Hasil analisis data univariat pada penelitian ini yang meliputi usia, pendidikan, masa kerja, keikutsertaan dalam pelatihan kebidanan komplementer, sumber informasi tentang praktik kebidanan komplementer digambarkan dalam tabel berikut :

Tabel 1: Distribusi Frekuensi karakteristik responden ditinjau dari Praktik Kebidanan Komplementer.

\begin{tabular}{|c|c|c|c|c|}
\hline \multirow{3}{*}{ Karakteristik } & \multicolumn{4}{|c|}{ Praktik Kebidanan Komplementer } \\
\hline & \multicolumn{2}{|c|}{ Melaksanakan } & \multicolumn{2}{|c|}{ Tidak Melaksanakan } \\
\hline & $\begin{array}{l}\text { Frekuensi } \\
\text { (n) }\end{array}$ & $\begin{array}{c}\text { Presentase } \\
(\%)\end{array}$ & $\begin{array}{l}\text { Frekuensi } \\
\text { (n) }\end{array}$ & $\begin{array}{c}\text { Presentase } \\
(\%)\end{array}$ \\
\hline \multicolumn{5}{|c|}{ (iv) $(2)$} \\
\hline a. $\leq 40$ Tahun & 30 & 83,3 & 6 & 11,8 \\
\hline b. $>40$ Tahun & 5 & 31,2 & 11 & 68,8 \\
\hline \multicolumn{5}{|l|}{ Pendidikan } \\
\hline a. Diploma 4 & 16 & 57,1 & 12 & 42,9 \\
\hline b. Diploma 3 & 19 & 79,2 & 5 & 20,8 \\
\hline \multicolumn{5}{|l|}{ Masa Kerja } \\
\hline a. $>10$ tahun & 32 & 80 & 8 & 20 \\
\hline b. $\leq 10$ tahun & 3 & 25 & 9 & 75 \\
\hline \multicolumn{5}{|l|}{ Pelatihan Komplementer } \\
\hline a. Pernah & 32 & 82,1 & 7 & 17,9 \\
\hline b. Tidak Pernah & 3 & 23,1 & 10 & 76,9 \\
\hline \multicolumn{5}{|l|}{ Sumber Informasi } \\
\hline a. Baik & 31 & 79,5 & 8 & 20,5 \\
\hline c. Kurang & 4 & 30,8 & 9 & 69,2 \\
\hline
\end{tabular}

Berdasarkan tabel di atas dapat dilihat bahwa sebagian besar $(65,7 \%)$ responden yang telah melaksanakan praktik kebidanan komplementer berusia kurang atau sama dengan 40 tahun, 54,3\% berlatarbelakang pendidikan diploma 4, dengan masa kerja terbanyak kurang atau sama dengan 10 tahun sebesar 82,9\%. Responden telah melaksakan praktik kebidanan komplementer sebagian besar $(68,6 \%)$ pernah mengikuti pelatihan komplementer dan $54,3 \%$ telah cukup mendapatkan informasi dari sumber informasi. $60 \%$ responden yang melaksanakan praktik kebidanan komplementer mempunyai pengetahuan yang cukup tentang praktik kebidanan komplementer dan $60 \%$ bersikap positif terhadap praktik kebidanan komplementer.

\section{Analisis Bivariat}

Hasil Penelitian ini juga menyajikan analisis hubungan variabel usia, pendidikan, masa kerja, keikutsertaan pelatihan, sumber informasi di Wilayah Kerja Kota Metro disajikan dalam tabel 2 berikut:

Tabel 2: Hubungan Antara Faktor Usia, Pendidikan, Masa Kerja, Keikutsertaan Pelatihan, Sumber Informasi.

\begin{tabular}{|c|c|c|c|c|c|c|c|}
\hline \multirow{3}{*}{ Karakteristik } & \multicolumn{4}{|c|}{$\begin{array}{l}\text { Praktik Kebidanan } \\
\text { Komplementer }\end{array}$} & \multirow{2}{*}{\multicolumn{2}{|c|}{ Jumlah }} & \multirow{3}{*}{$\stackrel{\rho}{\mathrm{OR}}$} \\
\hline & \multicolumn{2}{|c|}{ Melaksanakan } & \multicolumn{2}{|c|}{$\begin{array}{c}\text { Tidak } \\
\text { Melaksanakan }\end{array}$} & & & \\
\hline & $\mathrm{n}$ & $\%$ & $\mathrm{n}$ & $\%$ & $\mathrm{n}$ & $\%$ & \\
\hline \multicolumn{8}{|l|}{ Usia } \\
\hline a. $\leq 40$ Tahun & 30 & 83,3 & 6 & 11,8 & 36 & 100 & 0,001 \\
\hline $\begin{array}{l}\text { b. }>40 \text { Tahun } \\
\text { Pendidikan }\end{array}$ & 5 & 31,2 & 11 & 68,8 & 16 & 100 & 11 \\
\hline a. Diploma 4 & 16 & 57,1 & 12 & 42,9 & 28 & 100 & 0,164 \\
\hline $\begin{array}{l}\text { b. Diploma } 3 \\
\text { Masa Kerja }\end{array}$ & 19 & 79,2 & 5 & 20,8 & 24 & 100 & 0,3 \\
\hline a. $>10$ tahun & 32 & 80 & 8 & 20 & 40 & 100 & 0,001 \\
\hline b. $\leq 10$ tahun & 3 & 25 & 9 & 75 & 12 & 100 & 12 \\
\hline \multicolumn{8}{|l|}{ Pelatihan } \\
\hline a. Pernah & 32 & 82,1 & 7 & 17,9 & 39 & 100 & 0,000 \\
\hline b. Tidak Pernah & 3 & 23,1 & 10 & 76,9 & 13 & 100 & 15 \\
\hline \multicolumn{8}{|l|}{ Sumber Informasi } \\
\hline a. Baik & 31 & 79,5 & 8 & 20,5 & 39 & 100 & 0,002 \\
\hline c. Kurang & 4 & 30,8 & 9 & 69,2 & 13 & 100 & 8,7 \\
\hline
\end{tabular}

Berdasarkan tabel di atas dapat diketahui bahwa variabel usia, masa kerja, pelatihan komplementer, sumber informasi mempunyai hubungan bermakna dengan praktik kebidanan komplementer $(\mathrm{OR}=11$; IK $95 \%=2,78-43,4 ; \mathrm{p}>0,001, \mathrm{OR}=12$; IK $95 \%=2,627-54,815 ; \mathrm{p}>0,001, \mathrm{OR}=15 ; \mathrm{IK}$ $95 \%=3,3-70,2 ; \mathrm{p}>0,001, \quad \mathrm{OR}=8,7 ; \mathrm{IK}$ $95 \%=2,126-35,752 ; \mathrm{p}>0,001$, namun variabel pendidikan mempunyai hubungan yang tidak bermakna terhadap praktik kebidanan komplementer. $\quad(\mathrm{OR}=0,3$; IK $95 \%=0,102-1,209 ; \mathrm{p}>0,001)$.

\section{PEMBAHASAN}

\section{Hubungan Usia Bidan terhadap praktik Kebidanan Komplementer.}

Usia merupakan faktor individu yang sangat berperan dalam pembentukan tingkat kedewasaan seornag individu. Pada penelitian ini diketahui terdapat hubungan 
antara usia bidan dengan praktik kebidanan komplementer.

Hal ini sejalan dengan Penelitian Gita (2017) bahwa pelaksanaan pelayanan kebidanan komplementer pada BPM di Kab Klaten terbanyak adalah usia produktif yaitu 36-45 tahun. Kategori umur $\leq 40$ merupakan kelompok bidan terbanyak di wilayah kerja Kota Metro, dan merupakan pemberi pelayanan kebidanan di Kota Metro.

Usia mencerminkan kematangan dalam berfikir, pengalaman yang menjadi dasar dalam bekerja serta menggambarkan kompetensi atau kemampuan seseorang. Umur dari seorang individu sangat menentukan kemampuan dalam bekerja atau kinerjanya. Umur juga berhubungan dengan pengetahuannya dalam merespon atau melaksanakan suatu kegiatan dalam meningkatkan kinerjanya. Hal ini sesuai dengan hasil penelitian Gita (2017) Usia produktif memiliki tingkat kedewasaan yang baik sehingga memiliki kemampuan mengambil keputusan dalam memberikan pelayanan.

Usia akan mempengaruhi produktivitas, tidak demikian halnya dengan profesi bidan, penelitian membuktikan usia dan kinerja tidak ada hubungan, tetapi sering diandaikan keterampilan individu terutama kecepatan, kecekatan, kekuatan dan koordinasi mengikis dengan berjalannya waktu.

Ada suatu keyakinan yang meluas bahwa produktivitas merosot sejalan dengan makin tuanya usia atau umur. Hal ini tidak sepenuhnya terbukti benar karena ada sebagian orang yang sudah tua tetapi masih energik. Walaupun pada usia muda seseorang bisa lebih produktif.

Adanya hubungan antara usia dengan praktik kebidanan komplementer ini dikarenakan bidan yang berusia produktif mempunyai kemampuan untuk melaksanakan praktik kebidanan komplementer mengikuti perkembangan zaman yang mulai mengedepankan pengobatan non konvensional. Bidan-bidan usia produktif bersikap terbuka atas perubahan teknik dalam memberikan terapi attau pelayanan kebidanan.
Bidan dengan usia yang produktif diharapkan dapat memberikan pelayanan kebidanan yang terbaik. Karena Pekerja yang lebih muda diasumsikan mampu bekerja dengan cekatan dan lebih sigap dalam memberikan pelayanan.

\section{Hubungan Pendidikan Bidan terhadap praktik Kebidanan Komplementer.}

Hasil penelitian menunjukkan bahwa tidak ada hubungan antara pendidikan bidan dengan praktik kebidanan komplementer. Hal ini bertentangan dengan teori yang menyatakan pendidikan dapat mempengaruhi sikap hidup seseorang terhadap lingkungannya pendidikan yang lebih tinggi akan menimbulkan suatu sikap yang memperhatikan peningkatan hidupnya juga bertentangan dengan penelitian Gita (2017) yang menyatakan semakin tinggi tingkat pendidikan formal akan mempunyai pengetahuan yang lebih tinggi dibandingkan dengan yang berpendidikan lebih rendah.

Pendidikan seseorang berhubungan dengan pengetahuannya dalam merespon atau melaksanakan suatu kegiatan dalam meningkatkan kinerjanya.

Tidak ada hubungan antara pendidikan dengan praktik kebidanan komplementer dikarenakan pendidikan pada jenjang diploma 4 tidak selalu mendapatkan pengetahuan lebih tentang praktik komplementer yang daapat diterapkan dalam kebidanan di bangku kuliah. Pengetahuan tentang praktik-praktik komplementer yang dapat diterapkan dalam praktik kebidanan dapat diketahui dari berbagai pelatihanpelatihan, pembelajaran dan pengalaman yang secara teknis banyak diikuti oleh bidanbidan pelaksana dengan latarbelakang pendidikan terakhirnya diploma 3 oleh karena itu faktor pendidikan tidak memberikan peran yang besar dalam pelaksanaan praktik kebidanan komplementer dalam penelitian ini. Perlunya peningkatan dan pembaharuan pengetahuan dan keterampilan dalam pelayanan kebidanan seperti penguasaan terapi-terapi nonkonvensional yang berdasarkan evidance base terutama untuk jenjang pendidikan diploma 4 
Hubungan Masa Kerja Bidan terhadap Praktik Kebidanan Komplementer.

Hasil penelitian menunjukkan bahwa terhadap hubungan antara masa kerja bidan dengan praktik kebidanan komplementer.

Siagian (2008) menyatakan "masa kerka menunjukkan berapa waktu atau lama seseorang bekerja pada masing-masing pekerjaan". Masa kerja atau lamanya bekerja membuat seseorang mempunyai wawasan yang luas serta membentuk pola pikir yang lebih efektif dalam menyelesaikan kendala yang terjadi dalam pekerjaan sesuai dengan pengalamannya selama bekerja.

Hasil dari penelitian ini sesuai dengan penelitian Gita (2017) yang menyatakan bidan yang melakukan pelayanan kebidanan komplementer sebagian besar dengan masa kerja 21-30 tahun. Status lama bekerja seseorang berhubungan dengan pengetahuan dan pengalaman dalam merespon atau melaksanakan suatu kegiatan dalam meningkatkan kinerjanya.

Rivai dan Mulyadi (2010) masa kerja yang lebih lama menunjukkan pengalaman yang lebih seseorang dibandingkan rekan kerja lainnya yang mempunyai masa kerja lebih sedikit. Menurut Gibson (1996) lamanya masa tugas dan pengalaman dalam pengelolaan masalah atau kasus akan berpengaruh terhadap keterampilan seseorang.

Hasil penelitian ini sesuai bahwa bidan dengan masa kerja lebih lama akan menghayati dalam melaksakan peran fungsi dan kompetensinya secara maksimal. Semakin lama bidan bekerja maka akan semakin baik dalam memjalankan perannya sebagai pemberi pelayanan khususnya melakukan praktik kebidanan komplementer.

\section{Hubungan Keikutsertaan bidan dalam pelatihan komplementer terhadap praktik Kebidanan Komplementer}

Hasil penelitian menunjukkan bahwa ada hubungan antara pelatihan bidan dengan praktik kebidanan komplementer. Hasil penelitian ini ada $82,1 \%$ bidan yang telah mengikuti pelatihan komplementer telah memberikan pelayanan kebidanan komplementer sesuai dengan kompetensi yang didapatkannya dalam pelatihan hai ini menunjukkan sesuai teori Pelatihan sebagai salah satu upaya untuk mengembangkan kemampuan teoritis dan keterampilan dalam melakukan pekerjaannya. Hal ini sejalan dengan penelitian Erlina (2011) yang menyatakan ada hubungan yang bermakna antara pelatihan dengan kinerja bidan. Dan didukung oleh teori menurut Handoko (2008) pelatihan bertujuan untuk menutupi kesenjangan antara kemampuan petugas dengan tuntutan tugasnya dan untuk mencapai sasaran pekerjaan yang telah ditetapkan. Pelatihan juga akan memperbaiki penguasaaan berbagai keterampilan dan teknik pelaksanaan kerja tertentu secara rinci dan rutin serta dapat dilaksanakan secara formal.

Keikutsertaan bidan dalam pelatihanpelatihan praktik komplementer khususnya kebidanan sangat mempengaruhi seseorang untuk melakukan praktik kebidanan komplementer. Bidan yang telah mengikuti pelatihan akan mendapatkan pengetahuan dan keterampilan dan akan bersikap positif terhadap terapi-terapi komplementer yang telah diajarkan sehingga akan menerapkan dalam pelayanan kebidanan yang dialakukan.

\section{Hubungan sumber informasi yang di akses oleh Bidan terhadap praktik - praktik komplementer terhadap praktik Kebidanan Komplementer}

Hasil penelitian menunjukkan bahwa ada hubungan antara sumber informasi bidan dengan praktik kebidanan komplementer. Hasil penelitian ini sejalan dengan penelitian Rohmawati (2011) dalam Taufia (2017) keterpaparan informasi kesehatan terhadap individu kan mendorong terjadinya prilaku kesehatan.

Sumber informasi adalah segala sesuatu yang menjadi pelantara dalam menyampaikan informasi, media informasi untuk komunikasi massa. Sumber Informasi dapat diperoleh melalui media cetak, elektronik dan atau melalui pelatihanpelatihan. (Notoatmodjo (2003). Informasi yang diperoleh dari berbagai sumber akan mempengaruhi tingkat pengetahuan seseorang.

Semakin banyak seseorang mampu mendapatkan informasi dari berbagai sumber 
informasi maka akan bertambah pengetahuan sesorang terhadap objek maka kecendrungan seseorang akan bersikap baik mengenai suatu hal tersebut sehingga pada akhirnya akan terjadi perubahan prilaku kesehatan seperti dalam penelitian ini yaitu mempraktikkan kebidanan komplementer dalam memberikan pelayanan kebidanan.

\section{KESIMPULAN}

Ada hubungan bermakna antara variabel usia, masa kerja, keikutsertaan pelatihan, dan sumber informasi, pengetahuan dan sikap bidan PMB dengan praktik Kebidanan Komplementer. Saran bagi bidan pada BPM agar meningkatkan pengetahuan dan keterampilan tentang praktik kebidanan komplementer yang berbasis penelitian dengan mengikuti pelatihan-pelatihan agar mampu menerapkan terapi-terapi non konvensional/komplementer dalam memberikan pelayanan kebidanan.

\section{DAFTAR PUSTAKA}

Eisenberg, D. M., Davis, R. B., Ettner, S. L., Appel, S., Wilkey, S., Van Rompay, M., \& Kessler, R. C. (1998). Trends in alternative medicine use in the United States, 1990-1997: results of a followup national survey. Jama, 280(18), 1569-1575.

Erlina. (2011). Faktor-Faktor Yang Berhubungan Dengan Kinerja Bidan Desa Dalam Pencapaian Target Cakupan K4 Di Kabupaten Parigi Moutong Provinsi Sulawesi Tengah. Skripsi. Fakultas Kesehatan Masyarakat UI.

Gita. (2015. Pelaksanaan Pelayanan Kebidanan Komplementer pada Bidan Praktek Mandiri di Kabupaten Klaten. Gaster: Jurnal Ilmu Kesehatan. 12(1): 46-72.
Hall HG.at.al. 2012. Midwives'Support For Complementery and Alternative Medicine: a Literature Review. Women Birth. https://www.ncbi.nlm.nih.gov/ pubmed/21236745 diakses tanggal 20 September 2018.

Handoko, H. (2008). Manusia Manajemen Personalia dan Sumber Daya.

Kostania, G. (2015). Pelaksanaan Pelayanan Kebidanan Komplementer pada Bidan Praktek Mandiri di kabupaten Klaten. Gaster: Jurnal Kesehatan, 12(1), 46-72.

Masoumeh A.K. 2014. Complementary an alternative medicine in midwifery. Nurs Midwevery Studen. June 2014;3(2):ei19449.

Notoatmodjo, S. (2003). Pendidikan dan Prilaku. Rineka Cipta: Jakarta.

Rivai, V., \& Mulyadi, D. (2010). Kepemimpinan \& Perilaku Organisasi, Rajawali Pers: Jakarta

Supardi et al., (2010). Penggunaan Obat Tradisional Dalam Upaya Pengobatan Sendiri di Indonesia (Analisis Data Susnas Tahun 2007). Buletin Penelitian Kesehatan.

Wootton, J. C., \& Sparber, A. (2001). Surveys of complementary and alternative medicine: part IV. Use of alternative and complementary therapies for rheumatologic and other diseases. The Journal of Alternative \& Complementary Medicine, 7: 715-721.

World Health Organization. (2012). Traditional Medicine Strategy 20142023. WHO Library Cataloguing-InPublication Data. http://www.searo.who.int/entity/health _situation_trends/who_trm_strategy_20 14-2023.pdf diakses tanggal 20 September 2018.

World Health Organization. (2011) The World Medicine Situation Rational Use of Medicine. Geneva, 2011. http://www.who.int/medicines/areas/po licy/world_medicines_situation/en/ diakses tanggal 20 September 2018. 